\title{
Extrusão dos implantes em portadores de cavidade anoftálmica
}

\author{
Anophthalmic cavity and implant extrusion
}

\author{
Silvana Artioli Schellini ${ }^{1}$ \\ Flavia Keiko Ichida ${ }^{2}$ \\ Carlos Roberto Padovani ${ }^{3}$
}

\section{RESUMO}

Objetivo: Avaliar as características dos portadores de cavidades anoftálmicas que desenvolveram extrusão do implante. Métodos: Estudo retrospectivo, observacional, tendo sido avaliados 37 portadores de cavidade anoftálmica que tiveram extrusão do implante de cavidade, na Faculdade de Medicina de Botucatu-UNESP. Resultados: As extrusões ocorreram em cavidades enucleadas ou evisceradas, a maioria delas submetidas a cirurgia em decorrência de phthisis bulbi ou trauma, em geral de 1 a 2 anos após a cirurgia inicial. A deiscência precedeu a extrusão em todos os casos, tendo a extrusão ocorrido com todos os tipos de implantes empregados. Conclusão: Após a colocação de implantes de cavidade podem ocorrer complicações. A deiscência e extrusão das esferas são possibilidades que podem requerer nova intervenção cirúrgica, para a qual o paciente e o oftalmologista devem estar preparados.

Descritores: Enucleação ocular; Implantes orbitários/efeitos adversos; Doenças orbitárias; Hidroxiapatitas; Elastomeros de silicone; Esclera

\section{INTRODUC̣̃̃O}

Nos últimos anos, a reconstrução da cavidade anoftálmica vem passando por profundas alterações, com mudança nos materiais, formatos dos implantes e métodos de utilização das esferas de cavidade ${ }^{(1-3)}$.

Entretanto, apesar do apelo dos novos materiais para a mobilidade dos implantes, a possibilidade de complicações existe, dentre elas, a mais temida pelo cirurgião é a extrusão do implante.

Este estudo foi realizado com o objetivo de avaliar portadores de cavidade anoftálmica que evoluíram com extrusão do implante, procurando estabelecer fatores que possam concorrer para a existência deste problema.

\section{MÉTODOS}

Foi realizado estudo retrospectivo e observacional, avaliando-se 37 portadores de cavidade anoftálmica, operados na Faculdade de Medicina de Botucatu - UNESP, e que apresentaram extrusão da prótese da cavidade orbitária.

Foram analisados os seguintes parâmetros: idade, sexo, causa da perda do bulbo ocular, tipo de cirurgia realizada, tipo e tamanho do implante utilizado, deiscência e extrusão apresentadas no pós-operatório e intervalo de tempo entre a colocação e a extrusão do implante.

Todos os pacientes que foram enucleados tiveram a colocação da esfera envolta em esclera conservada em glicerina a $5^{\circ} \mathrm{C}$. 
Os resultados foram submetidos à avaliação estatística pela freqüência de ocorrência.

\section{RESULTADOS}

Dos 37 pacientes que tiveram extrusão do implante, $79,5 \%$ eram homens e $20,5 \%$ mulheres. A causa da perda do bulbo ocular, distribuída de acordo com o procedimento realizado, foi mais freqüentemente o trauma, phthisis bulbi e endoftalmite e quanto ao tipo de cirurgia, $28(75,7 \%)$ dos pacientes foram eviscerados e 9 (24,3\%), enucleados (Tabela 1$)$.

A idade dos pacientes variou de 2 a 83 anos, tendo sido a perda do bulbo ocular mais freqüente nos adultos jovens e nos idosos. A esfera mais utilizada foi a de PMMA (polimetilmetacrilato), seguida pelo polímero vegetal $(21,7 \%)$, sendo a de diâmetro $18 \mathrm{~mm}$ a mais utilizada (27\%) (Tabela 2).

Com relação ao tipo de implante, as extrusões ocorreram mais com esferas de PMMA (Tabela 3).

Todos os pacientes que foram aqui estudados apresentaram em algum momento no pós-operatório deiscência conjuntival e/ou escleral (Tabela 4).

A extrusão da esfera ocorreu mais freqüentemente 1 a 2 anos após a cirurgia. Após a $1^{\underline{a}}$ extrusão, 23 pacientes $(62,2 \%)$ receberam novo implante no mesmo ato cirúrgico e 14 (37,8\%), receberam o implante tardiamente. Houve necessidade de reoperação em $21,6 \%$ dos pacientes, tendo ocorrido uma $2^{\underline{a}}$ extrusão, geralmente precedida por nova deiscência de sutura (Tabela 5).

\begin{tabular}{|c|c|c|c|c|}
\hline \multirow[b]{2}{*}{ Causa } & \multicolumn{2}{|c|}{ Tipo cirurgia } & \multirow[b]{2}{*}{ Total } & \multirow[b]{2}{*}{ Porcentagem } \\
\hline & Enucleação & Evisceração & & \\
\hline Phthisis bulbi & 2 & 5 & 7 & 18,9 \\
\hline Trauma & 0 & 7 & 7 & 18,9 \\
\hline Úlcera de córnea & 1 & 6 & 7 & 18,9 \\
\hline Endoftalmite & 0 & 5 & 5 & 13,5 \\
\hline Glaucoma absoluto & 0 & 5 & 5 & 13,5 \\
\hline Anoftalmia clínica & 3 & 0 & 3 & 8,1 \\
\hline Microftalmia & 2 & 0 & 2 & 5,4 \\
\hline Tumor & 1 & 0 & 1 & 2,7 \\
\hline Total & 9 & 28 & 37 & 100,0 \\
\hline
\end{tabular}

\begin{tabular}{|lcc|}
\hline \multicolumn{2}{|c|}{ Tabela 2. Diâmetro dos implantes e freqüência de utilização } \\
$\begin{array}{l}\text { Diâmetro do } \\
\text { implante (em } \mathbf{~ m m ) ~}\end{array}$ & $\begin{array}{c}\text { Freqüência de } \\
\text { utilização }\end{array}$ & $\begin{array}{c}\text { Porcentagem } \\
15\end{array}$ \\
16 & 1 & 2,7 \\
17 & 4 & 8,1 \\
18 & 4 & 10,9 \\
19 & 10 & 27,0 \\
20 & 2 & 5,4 \\
Sem informação & 2 & 5,4 \\
Total & 14 & 37,9 \\
& 37 & 100,0
\end{tabular}

\section{DISCUSSÃO}

A maioria dos portadores de cavidade anoftálmica que evoluiu com complicações era do sexo masculino e em idade produtiva, provavelmente porque este é o perfil dos indivíduos que perdem o bulbo ocular com maior freqüência ${ }^{(1-2)}$.

As causas de perda do bulbo ocular foram trauma, phthisis bulbi e úlcera de córnea. Considerando o trauma como fator causal principal da perda do olho(4), as complicações são mais importantes neste grupo de pacientes.

Quanto ao tipo de cirurgia com ocorrência de extrusão, $75,7 \%$ haviam sido submetidos à evisceração. Segundo alguns autores, a evisceração está mais relacionada à extrusão ${ }^{(5)}$. Entretanto, em nosso meio, é mais freqüente a indicação da evisceração por haver menor manipulação das estruturas orbitárias, o que provavelmente explicaria o maior número de complicações neste grupo de indivíduos.

Quando o procedimento foi a enucleação, foi utilizada esfera envolta em esclera. Este procedimento pode também ser feito usando outros materiais, como o pericárdio bovino ${ }^{(6)}$ e a tela de Mersilene ${ }^{(7)}$. Porém, com qualquer destes materiais é possível ter extrusão do implante ${ }^{(6)}$.

\begin{tabular}{|lcc|}
\hline \multicolumn{3}{|c|}{ Tabela 3. Tipo de implante utilizado e freqüência de utilização } \\
Tipo & Freqüência de utilização & Porcentagem \\
PMMA & 11 & 29,7 \\
Polímero vegetal & 8 & 21,7 \\
Hidroxiapatita sintética & 4 & 10,8 \\
Polietileno poroso & 3 & 8,1 \\
Sem informação & 11 & 29,7 \\
Total & 37 & 100,0 \\
\hline
\end{tabular}

Tabela 4. Complicações pós-operatórias no tratamento das 37 cavidades anoftálmicas

\begin{tabular}{lcc} 
Complicação & Número & Porcentagem \\
Deiscência & 37 & 100,0 \\
Secreção & 7 & 18,9 \\
Fundo-de-saco raso & 5 & 13,5 \\
Retração do saco escleral & 5 & 13,5 \\
Celulite orbitária & 1 & 2,7 \\
Sem informação & 3 & 8,1 \\
\hline
\end{tabular}

Tabela 5. Intervalo de tempo entre a colocação do implante e a extrusão

\begin{tabular}{lcc} 
Tempo & Número & Porcentagem \\
1 semana a 1 mês & 5 & 13,5 \\
1 mês a 6 meses & 6 & 16,2 \\
6 meses a 1 ano & 6 & 16,2 \\
1 ano a 2 anos & 8 & 21,6 \\
Mais de 2 anos & 7 & 18,9 \\
Sem informação & 5 & 13,5 \\
Total & 37 & 100,0 \\
\hline
\end{tabular}


É conhecido que esferas maiores possuem maior tendência à extrusão, o que não se confirma pelos dados apresentados, uma vez que o implante que mais extruiu apresentava diâmetro de $18 \mathrm{~mm}$, apesar de se ter grande número de indivíduos em que este dado era desconhecido.

Quanto ao tipo de implante, a esfera de PMMA foi a que mais freqüentemente teve extrusão. Entretanto, esta esfera é a mais utilizada no Serviço e que mais tempo de observação possui, uma vez que vem sendo empregada há cerca de duas décadas. A nosso ver, a extrusão pode estar relacionada com alterações do tipo contração da capa escleral no setor posterior, constatada em alguns dos pacientes durante o procedimento cirúrgico, com afinamento da mesma e da conjuntiva no setor anterior, levando à exposição da esfera. $\mathrm{O}$ fato de se ter esta contração tecidual no pólo posterior, dificulta o tratamento das deiscências quando se faz a opção por fechamento ou enxertia, ocorrendo novas deiscências, principalmente quando a deiscência é grande.

No caso da esfera de polímero vegetal e considerando-se este tipo de implante como integrado, observaram-se 21,6\% de extrusões. Estas esferas possuem a superfície muito áspera, o que torna as deiscências mais freqüentes, o que nos levou a abandonar o uso deste material nas cirurgias de reconstrução da cavidade anoftálmica.

A complicação pós-operatória mais observada com qualquer das esferas foi a deiscência da conjuntiva, seguida da exposição da esclera, sendo este o fator inicial que terminou com a extrusão dos implantes. Após a deiscência escleral, a exposição da esfera é dificilmente corrigida, com qualquer tipo de esfera, mesmo utilizando enxertos e retalhos, talvez pela contratura da capa escleral no setor posterior.

Vários tipos de procedimentos cirúrgicos são sugeridos para tratamento das deiscências e exposição da esfera, incluindo colocação de tecidos autólogos como enxertos livres (removidos do pálato duro, conjuntiva, mucosa bucal, pele, enxerto dermoadiposo) ou retalhos (conjuntiva e tarso) ${ }^{(8)}$. Entretanto, no caso das esferas não integradas, os enxertos ficam sobre áreas não vascularizadas, não sendo nutridos e necrosam. Os implantes integrados e que já se encontram vascularizados podem fornecer suprimento para os enxertos, mas levam a desvantagem de possuir superfície rugosa, possuir substâncias químicas potencialmente irritantes e que interferem na cicatrização $0^{(8-10)}$.

Muitas vezes, ao se ter uma extrusão com o uso de esfera não integrada, o cirurgião procura uma esfera integrada para a reoperação, acreditando que se possa ter menor chance de complicação no pós-operatório. Entretanto, os implantes integrados são confeccionados com materiais de superfície áspera pela presença dos poros, o que provoca inflamação crônica e deiscência da conjuntiva e esclera ${ }^{(9)}$. Outro problema seria que alguns implantes contém impurezas, que podem provocar reação inflamatória na órbita ${ }^{(11)}$.

Comparando-se índices de exposição das esferas não integradas (de silicone) e de hidroxiapatita natural, foram observadas $11 \%$ de exposição do implante de hidroxiapatita e nenhum caso com as esferas de silicone, sugerindo-se que os implantes não integrados causariam menos complicações ${ }^{(9)}$.

As deiscências são possíveis com todos os tipos de implantes que se utilize, iniciando-se por afinamento da conjuntiva, exposição da esclera, seguida de abertura da esclera e exposição da esfera ${ }^{(12)}$, podendo acontecer precoce ou tardiamente.

As causas para deiscência precoce seriam: má técnica cirúrgica, implantes muito grandes, doenças sistêmicas associadas (como o diabetes, artrite reumatóide), cavidades contraídas, reação biológica contra o implante ${ }^{(10,13)}$.

Interessante notar que a maioria dos indivíduos do presente estudo apresentou extrusão tardia da esfera. As deiscências tardias são o resultado de próteses externas mal adaptadas ${ }^{(12)}$. O movimento constante da esfera pode levá-la a tocar a prótese externa, resultando em afinamento da conjuntiva e esclera, até que exista a deiscência e exposição da esfera.

Quando se trata de implantes integrados com deiscências grandes, a contaminação bacteriana das esferas expostas é uma possibilidade, o que leva à necessidade de remoção da esfera, pois nem o tratamento tópico ou sistêmico, elimina completamente a infecção $o^{(14)}$.

Após a extrusão do implante, nova intervenção cirúrgica se faz necessária. A maioria dos indivíduos foi reoperada no mesmo ato, ou seja, quando da extrusão da esfera. A nosso ver, esta é a melhor conduta, pois evitará maior contração tecidual e orbitária e possibilitará melhor recuperação estética do paciente.

A prevenção de complicações, como a deiscência e a extrusão das esferas, pode ser feita usando boa técnica operatória, realizando meticulosa sutura em dois planos, sem tensão, com tecidos bem vascularizados sobre o implante, empregando esferas que tenham superfície pouco rugosa, leves, centradas no cone muscular, colocadas na órbita em posição profunda e revestidas na sua superfície anterior ${ }^{(15)}$.

É muito importante cuidar muito bem das próteses externas que não devem ter contato agressivo com a superfície conjuntival e devem ser revisadas periodicamente, uma vez que há mudanças na posição dos tecidos orbitários, alterando a interface esfera/prótese externa com o passar dos anos.

\section{CONCLUSÃO}

A reconstrução da cavidade anoftálmica é difícil de ser feita. Complicações como a deiscência e a expulsão das esferas são possibilidades que podem requerer nova intervenção cirúrgica, para a qual o oftalmologista deve estar preparado.

\section{ABSTRACT}

Purpose: To evaluate the characteristics of patients with anophthalmic cavity who developed sphere extrusion. Methods: A retrospective observational study was done evaluating 37 patients with anophthalmic cavity and sphere extrusion at the "Faculdade de Medicina de Botucatu-UNESP". 
Results: Extrusion was observed in enucleated and eviscerated cavities. The majority of the patients had the eye removed because of phthisis bulbi or trauma and the extrusion happened 1 or 2 years after the surgery. Extrusion was preceded by conjunctival dehiscence and exposure of the sphere and occurred with all used implants. Conclusion: Complications after orbital implant placement are a possibility. Dehiscence and sphere extrusion may happen and another surgery would be necessary. The patient and the ophthalmologist have to be prepared for this.

Keywords: Eye enucleation; Orbital implants/adverse effects; Orbital diseases; Hydroxyapatites; Silicone elastomers; Sclera

\section{REFERÊNCIAS}

1. Den Tonkelaar J, Henkes HE, Leersum GK. Herman Snellen (1834-1908) and Muller "reform-auge". A short history of the artificial eye. Doc Ophthalmol. 1991;77(4):349-54.

2. Perry AC. Integrated orbital implants. Adv Ophthalmic Plast Reconstruct Surg. 1988;8:75-81.

3. Rubin PA, Popham JK, Bilyk JR, Shore JW. Comparison of fibrovascular ingrowth into hydroxyapatite and porous polyethylene orbital implants. Ophthal Plast Reconstr Surg. 1994;10(2):96-103.
4. Schellini SA, Silva MR, Hashimoto M, Rodrigues AC. Cavidade anoftálmica: causas, reconstrução e complicações. Rev Bras Oftamol. 1994;53(3):517-22.

5. Zolli CL. Implant extrusion in eviscerations. Ann Ophthalmol. 1988;20(4): 127-32,135.

6. Gupta M, Puri P, Rennie IG. Use of bovine pericardium as a wrapping material for hydroxyapatite orbital implants. Br J Ophthalmol. 2002;86(3):288-9.

7. Hughes JD, Downes RN, Kemp E. The mersilene covered intraorbital implant. Eye. 1992;6(Pt 5):484-6.

8. Kim YD, Goldberg RA, Shorr N, Steinsapir KD. Management of exposed hydroxyapatite orbital implants. Ophthalmology. 1994;101(10):1709-15. Comment in: Ophthalmology. 1995;102(4):528-9.

9. Nunery WR, Heinz GW, Bonnin JM, Martin RT, Cepela MA. Exposure rate of hydroxyapatite spheres in anophthalmic socket: histopathologic correlation and comparison with silicone sphere implants. Ophthal Plast Reconstr Surg. 1993;9(2):96-104

10. Buettner H, Bartley GB. Tissue breakdown and exposure associated with orbital hydroxyapatite implants. Am J Ophthalmol. 1992;113(6):669-73.

11. Jordan DR, Pelletier CR, Gilberg TS, Brownstein S, Grahovac SZ. A new variety of hydroxyapatite: the Chinese implant. Ophthal Plast Reconstr Surg. 1999; 15(6):420-4.

12. Shields CL, Shields JA, De Potter P, Singh AD. Problems with the hydroxyapatite orbital implant: experience with 250 consecutive cases. Br J Ophthalmol. 1994;78(9):702-6.

13. Goldberg RA, Holds JB, Ebrahimpour J. Exposed hydroxyapatite orbital implants. Report of six cases. Ophthalmology. 1992;99(5):831-6.

14. Wilson MW, Wobig JL, Dailey RA. Infection of a porous polyethylene orbital implant with Canocytophaga. Ophthal Plast Reconstr Surg. 1998;14(6):398-402.

15. Christmas NJ, Gordon CD, Murray TG, Tse D, Johnson T, Garonzik S, et al. Intraorbital implants after enucleation and their complications: a 10-year review. Arch Ophthalmol. 1998;116(9):1199-203. 